\title{
An Agar Plate Method for Rapid Screening of Rhizobium for Tolerance to Acid-Aluminum Stress ${ }^{1}$
}

\author{
A. AYANABA, S. ASANUMA, AND D. N. MUNNS ${ }^{2}$
}

\begin{abstract}
An agar plate method has been developed for the rapid, preliminary screening of large numbers of rhizobia for tolerance to acidity and aluminum (acid-Al). Media containing $\mathrm{pH}$ indicators are used, and distinguish true tolerance from cases where growth depends on a previous pH shift. Strains which were highly tolerant or sensitive to acid Al on agar behaved similarly in defined liquid media. Strains that formed dry, pinpoint colonies were more sensitive to acid-AI than those that formed large, gummy colonies.
\end{abstract}

Additional Index Words. acidity, aluminum, cowpea rhizobia, pH indicators, Rhizobium japonicum.

Ayanaba, A., S. Asanuma, and D.N. Munns. 1983. An agar plate method for rapid screening of Rhizobium for tolerance to acid-aluminum stress. Soil Sci. Soc. Am. J. 47:256-258.

METHODS have been developed recently for the preselection of Rhizobium strains tolerant of the soil acidity factors: aluminum, phosphate, and acidity (Date and Halliday, 1978; Keyser and Munns, 1979) and so of possible value as inoculant strains in the tropics. In these studies test strains are added to the stress media, incubated, and then examined for turbidity. In more refined tests, incubated cultures are monitored for cell multiplication prior to detectable $\mathrm{pH}$ changes.

Screening for tolerance of acidity and $\mathrm{Al}$ can be vitiated by shifts in $\mathrm{pH}$, which rhizobia sometimes induce depending on the buffering and particular composition of the medium (Date and Halliday, 1978). In agar media, local neutralization at the point of inoculation could become specially important, especially with large inocula. We report on an agar plate method that permits rapid screening of large numbers of rhizobia for tolerance to

\footnotetext{
' Contribution from the International Institute of Tropical Agriculture (IITA), P.M.B. 5320, Ibadan, Nigeria, and the Dep. of Land, Air and Water Resources, Univ. of California, Davis, CA 95616. IITA Jour. Paper Ser. no. 217. Supported in part by a grant from the United Nations Development Programme

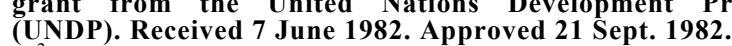

${ }^{2}$ Soil Microbiologists, IITA, Ibadan, Nigeria, and Professor of Soil Science, Univ. of California, Davis.
}

an acid-A1 stress; and the application of this method to the screening of 224 rhizobia belonging to Rhizobium japonicum and Rhizobium sp.

\section{MATERIALS AND METHODS}

Media

Two media containing the basal solution of Keyser and Munns (1979) but with galactose and arabinose, at $5 \mathrm{~g} / \mathrm{L}$ each, instead of mannitol were used to test the response of rhizobia to acid-Al stress. The basal solution contained $(\mu \mathrm{M})$ : $\mathrm{MgSO}_{4}, 300 ; \mathrm{CaCl}_{2}, 300$; FeEDTA, 10; KCI, 10; $\mathrm{MnCl}_{2}, 1$; $\mathrm{ZnSO}_{4}, 0.4 ; \mathrm{CuCl}_{2}, 0.1 ; \mathrm{Na}_{2} \mathrm{MoO}_{4}, 0.02 ; \mathrm{Co}\left(\mathrm{NO}_{3}\right)_{2}, 0.001$. In addition, the media contained $1.8 \mathrm{~g} / \mathrm{L}$ of sodium glutamate, 5 $\mu \mathrm{M} \mathrm{KH} \mathrm{PO}_{4}, 1.5 \mathrm{mM} \mathrm{KCl}$ and $20 \mathrm{~g} / \mathrm{L}$ of agar. The control (LP) medium contained the modified basal medium plus $0.005 \%$ bromcresol purple (BCP) indicator (Conn, 1957). The $\mathrm{pH}$ was adjusted to 7.0 with $1 N \mathrm{NaOH}$ before autoclaving and fell to 6.0 after autoclaving. The stress (AL) medium contained the modified basal medium, $0.005 \%$ bromcresol green (BCG) indicator (Conn, 1957), and $50 \mu \mathrm{M}$ Al. The $\mathrm{Al}$, as $5 \mathrm{mM} \mathrm{KAl}\left(\mathrm{SO}_{4}\right)_{2}$, was filtersterilized before addition to agar held at $47^{\circ} \mathrm{C}$. The $\mathrm{pH}$ was adjusted to 4.7 with $1 N \mathrm{HCl}$ before autoclaving; the final $\mathrm{pH}$ was 4.6 after the addition of Al. The agar media were poured into square petri plates $(100$ by $15 \mathrm{~mm})$ at $20 \mathrm{~mL} /$ plate and allowed to solidify. Plates were dried at $40^{\circ} \mathrm{C}$ for $3 \mathrm{~h}$ before inoculation.

Liquid forms of LP and AL media were similarly prepared, but without agar and indicator. They were dispensed at $20 \mathrm{~mL}$ per $50-\mathrm{mL}$ conical flask prior to autoclaving. Cooled, liquid $\mathrm{AL}$ medium received aluminum to provide $50 \mu \mathrm{M} \mathrm{Al}$.

\section{Rhizobia}

Rhizobia from the culture collection of the International Institute of Tropical Agriculture (IITA), Ibadan, Nigeria, were used in the tests. All nodulate cowpea (Vigna unguiculata) cultivar TVu 1190 and some, in addition, nodulate soybean (Glycine max) cultivar TGm 344.

\section{Determining the Inoculum Level}

Before inoculation, 16 equal squares were marked on the bottoms of triplicate petri plates of AL agar media. A loop calibrated to deliver $0.38 \pm 0.04 \mathrm{AL}$ was used to inoculate squares with tenfold dilutions of the test strains, containing 
from about $10^{2}$ to $10^{8}$ rhizobia/mL. The LP agar plates were similarly inoculated. The plates were incubated at $30^{\circ} \mathrm{C}$ and examined daily for growth and change in the colors of indicators over a 10 -d period.

\section{Plate Screening for Tolerance of Acid-Al Stress}

The plate method was used to screen 224 rhizobia of diverse origins. Triplicate plates of LP and AL media were inoculated with dilute suspensions (ca. $10^{6}$ to $10^{7}$ cells $/ \mathrm{mL}$ ) of each strain, prepared from yeast extract-mannitol (YEM) slant cultures. The plates were incubated at $30^{\circ}$ $\mathrm{C}$ and examined daily for growth and change of $\mathrm{pH}$ of the media over a 10 -d period.

\section{Correspondence Between Methods}

Two experiments were conducted to evaluate the correspondence between acid-Al tolerance on agar plates and in liquid media, and to examine the relationship between ammonia production and $\mathrm{pH}$ changes in the growth media.

\section{Experiment 1}

Twenty rhizobia identified as either tolerant or sensitive to acid-Al stress on agar media were used. Duplicate flasks of LP and AL media were inoculated with $0.04 \mathrm{~mL}$ of suspensions of the rhizobia in a diluent (Keyser and Munns, 1979) so as to provide $10^{2}$ to $10^{3}$ cells $/ \mathrm{mL}$. The LP and AL media without arabinose and galactose and in which sodium glutamate served as the source of carbon and nitrogen for growth were similarly inoculated. Flasks were incubated on a reciprocal shaker operating at 110 strokes/min at room temperature. The shaker was automatically switched on for $1 \mathrm{~h}$ every other hour. After $10 \mathrm{~d}(15 \mathrm{~d}$ for very slow growing strains), the optical density of the suspensions were determined at $470 \mathrm{~nm}$. The suspensions were centrifuged in the cold at $4,342 \mathrm{X}$ g for $20 \mathrm{~min}$, and the ammonium-N content (Mitchell, 1972) and $\mathrm{pH}$ of the supernatant fluid were determined.

\section{Experiment 2}

Two cowpea rhizobia, one (IRc 381) sensitive to and the other (IRc 353) tolerant of the acid-AI stress on agar media, were used. Eighteen flasks each of LP and AL media were inoculated with each strain and incubated as in Experiment 1. Initially and after 5, 10, 15, 20, and $25 \mathrm{~d}$, three flasks of each medium inoculated with each strain were removed from the shaker and the optical density, $\mathrm{pH}$, and ammonium- $\mathrm{N}$ content of each suspension were determined, as in Experiment 1.

\section{RESULTS AND DISCUSSION}

The rates of $\mathrm{BCP}$ and $\mathrm{BCG}$ used here are far below the $0.04 \%$ recommended for bacteriological work (Conn, 1957). Nonetheless, color changes of these indicators permitted early visual detection of $\mathrm{pH}$ shifts during rhizobial growth on agar plates.

Rhizobia that tolerate acid-Al grew and could be detected easily by the agar plate method. An inoculum of $0.4 \mu \mathrm{L}$ from a suspension of $10^{6}$ to $10^{7}$ rhizobia $/ \mathrm{mL}$ was best for distinguishing between acid-Al tolerance and sensitivity (Table 1). Growth of acid-Al tolerant strains was usually detected prior to a $\mathrm{pH}$ change. In some instances, growth and color change of the medium were observed on the same day. In such cases, more frequent observation than on a daily basis was required to ascertain whether growth preceded color change. By the 10th day when the incubation was usually terminated, all acid-Al tolerant strains showed appreciable growth, and several strains had rendered the AL medium sufficiently more alkaline or more acid than it originally was, producing
Table 1-Effect of cell concentration on the response of rhizobia to acid-Al by the agar plate method.

\begin{tabular}{|c|c|c|c|c|c|c|c|c|}
\hline \multirow{2}{*}{$\begin{array}{l}\text { Rhizobium } \\
\text { Strain } \neq\end{array}$} & \multirow{2}{*}{$\begin{array}{c}\text { No. of } \\
\text { rhizobia/mL } \\
\left(\times 10^{8}\right)\end{array}$} & \multicolumn{7}{|c|}{$\begin{array}{l}\text { Responseł in AL medium when indicated } \\
\text { dilutions were sources of inoculum }\end{array}$} \\
\hline & & 0 & $10^{-1}$ & $10^{-2}$ & $10^{-3}$ & $10^{-4}$ & $10^{-5}$ & $10^{-6}$ \\
\hline IRc 353 & 5.12 & + & + & + & + & + & + & - \\
\hline 381 & 7.92 & \pm & _- & - & - & - & - & - \\
\hline $516 \mathrm{~A}$ & 4.74 & + & + & + & \pm & \pm & \pm & - \\
\hline IRj $2144 B$ & 6.30 & + & + & \pm & - & - & - & - \\
\hline $2147 \mathrm{~B}$ & 0.84 & \pm & \pm & - & - & - & - & - \\
\hline 2163 & 6.84 & \pm & - & - & - & - & - & - \\
\hline
\end{tabular}

† Strains designated as IRc were isolated from cowpeas; those designated as IRj were isolated from soybeans.

$\ddagger$ Growth response by comparison with growth in LP medium: $+=$ good growth; \pm = fairly good growth; $\stackrel{ \pm}{=}$ poor growth; $-=$ no growth.

color halos around colonies. If plates were incubated for $25 \mathrm{~d}$, many of the strains sensitive to acid-Al still had not grown in the AL medium, even though growth in the LP medium was abundant. Proximity to acid-Al tolerant strains that altered the $\mathrm{pH}$ of the medium did not affect the response of sensitive strains. However, a few sensitive strains grew scantily in the AL medium, usually, after the 20th day. In any case, strains that are highly tolerant to acid-Al always showed significant growth within $10 \mathrm{~d}$, before $\mathrm{pH}$ change in the $\mathrm{AL}$ medium. Graham et al. (1982) used an agar plate method without $\mathrm{pH}$ indicators to preselect Rhizobium phaseoli, assuming that growth of single colonies was indicative of acid or $\mathrm{Al}$ tolerance.

Acid-Al tolerance of a large, diverse collection of rhizobia was readily detected using the agar plate method (Table 2). Tolerance of the acid-Al stress was found among both cowpea and soybean rhizobia. Rhizobial origin appeared to influence the response, as described in a previous study (Ayanaba and Wong, 1982), but on closer examination it appeared that colony type mattered more. Thus, strains that formed dry, pinpoint colonies on YEM agar were extremely sensitive to the acid-Al stress. When the proportion of "dry" strains from a particular source was high, the proportion of the total number of strains which tolerated the acid-Al stress was low. By contrast, most strains with large, gummy "wet" colonies tolerated the stress more.

When strains identified as tolerant or sensitive to acidAl on agar plates were subbed in liquid media, growth, as determined by optical density, was severely curtailed by the acid-Al stress among rhizobia previously identified on agar media as sensitive, but not those considered tolerant (Table 3). Some strains, e.g., IRc 353 and IRj

Table 2-Response of cowpea and soybean rhizobia to acid-Al stress on agar plates.

\begin{tabular}{|c|c|c|c|c|c|}
\hline \multirow{2}{*}{$\begin{array}{l}\text { Host of } \\
\text { isolation }\end{array}$} & \multirow{2}{*}{$\begin{array}{l}\text { Location/ } \\
\text { Source } †\end{array}$} & \multicolumn{2}{|c|}{ Number of rhizobia } & \multicolumn{2}{|c|}{ Growth in acid-Al } \\
\hline & & In test & Dry $\ddagger$ & No. $\S$ & $\%$ \\
\hline Cowpea & $\begin{array}{l}\text { Onne } \\
\text { Maradi } \\
\text { Other }\end{array}$ & $\begin{array}{l}46 \\
36 \\
16\end{array}$ & $\begin{array}{r}8 \\
35 \\
7\end{array}$ & $\begin{array}{c}27(13) \\
0 \\
6(4)\end{array}$ & $\begin{array}{c}58.7 \\
0 \\
37.5\end{array}$ \\
\hline Soybean & $\begin{array}{l}\text { Onne } \\
\text { Maradi } \\
\text { Other } \\
\text { Culture collection }\end{array}$ & $\begin{array}{l}50 \\
38 \\
14 \\
24\end{array}$ & $\begin{array}{r}23 \\
36 \\
0 \\
0 \\
13\end{array}$ & $\begin{array}{c}27(19) \\
9(2) \\
13(12) \\
5(2)\end{array}$ & $\begin{array}{l}54.0 \\
23.7 \\
92.9 \\
20.8\end{array}$ \\
\hline
\end{tabular}

† Onne is in Nigeria; soil has a pH of 4.6 and is highly leached. Maradi is in Niger Republic; soil has a pH of 6.1 and is subjected to desiccation and high temperatures.

‡ Rhizobia that form dry, pinpoint colonies on YEM agar.

$\S$ Numbers in parentheses are of highly tolerant strains; these grow to the same extent in AL and LP media. 
